\title{
Closure of a pharyngocutaneous fistula using a sternomastoid muscle flap
}

\author{
Rajagopalan Raman MS, Usha Devi Arumainathan FRCS
}

\begin{abstract}
R Raman, UD Arumainathan. Closure of a pharyngocutaneous fistula using a sternomastoid muscle flap. Can J Plast Surg 2005;13(1):49.

Presented here is a case of a pharyngocutaneous fistula which was closed primarily using a sternomastoid muscle flap, without skin coverage, thus obviating the need for a three-layered closure. Providing an intermediate cover was sufficient for the closure because the mucosal lining on the inside and the cutaneous covering on the outside grew using the muscle for support.
\end{abstract}

Key Words: Closure; Pharyngocutaneous fistula; Sternomastoid flap

\section{Fermeture d'une fistule pharyngo-cutanée à l'aide d'un lambeau musculaire sterno-cléido- mastoïdien}

\begin{abstract}
On présente ici un cas de fistule pharyngo-cutanée qui a été principalement refermée à l'aide d'un lambeau du muscle sterno-cléido-mastoïdien, sans couche cutanée, évitant ainsi le recours à une fermeture en trois couches. Il a été suffisant d'implanter une couche intermédiaire pour la réparation parce que la paroi muqueuse interne et la couche cutanée externe se sont développées à partir du support musculaire.
\end{abstract}

Ctandard management of postoperative pharyngocutaneous $\checkmark$ fistulas includes single-stage closure of the mucosal lining, intermediate layer and the covering squamous epithelial layer. Depending on the size, larger fistulas require two flaps, one for the inner lining and one for the cover, either of which includes a muscle layer for the intermediate cover (1). Myocutaneous flaps are among the various flaps that have been used (1); in particular, the sternomastoid myocutaneous flap has been used for the closure of oral and pharyngeal defects after oral surgery $(2-5)$. The sternomastoid by itself, without the cutaneous component, has been used to fill in the defect after a parotidectomy (6), with clavicle used for mandibular reconstruction (7).

Here, we present a case that describes a method in which the sternomastoid, by itself, without the cutaneous cover, is used for the closure of a pharyngocutaneous fistula, thus obviating the need for a three-layered closure.

\section{CASE PRESENTATION}

The patient developed a small suprastomal fistula in the midline on the eighth postoperative day after a total laryngectomy and a radical neck dissection for a carcinoma of the larynx. This fistula increased in size, reaching $4 \mathrm{~cm}$ (transverse) and $3 \mathrm{~cm}$ (vertical) after three weeks. Under general anesthesia, the original U-shaped incision skin flap was again raised to the base of the tongue, thus separating the mucous lining of the fistula. This procedure helped to make both the edges of the mucous lining and the cutaneous lining fresh. The sternomastoid muscle on the nonradical dissection side of the neck was exposed up to the sternal and clavicular attachment sites of the muscle, located beside the tracheostoma. An approximate measurement of the muscle, equivalent to the transverse measurement of the fistula $(4 \mathrm{~cm})$ was taken, and the sternomastoid muscle was divided above the sternal attachment and separated from the clavicular attachment of the muscle up to the level of the superior thyroid vessels. This muscle flap was then rotated medially and sutured to the remnants of the muscle and soft tissue on the opposite side, thus closing the fistula. A few stay sutures were inserted between the mucosal lining and the rotated muscle. The skin flap was returned to its original location. A few more stay sutures were inserted between the muscle and the raw cutaneous edges of the fistula. The cutaneous defect was covered with Vaseline gauze and nasogastric feeding was continued. The salivary leak stopped within a week and the cutaneous defect closed in three weeks.

\section{COMMENTS}

The sternomastoid muscle is supplied by the occipital vessel superiorly, the superior thyroid vessel in the middle and the thyrocervical trunk inferiorly. This muscle flap was based superiorly on the occipital and superior thyroid vessels supply. The inner mucosal lining and the outer cutaneous lining grew over the intermediate muscle support.

\section{REFERENCES}

1. Mazzola RF, Sambataro G. Guidelines for pharyngostome closure. Plast Reconstr Surg 1987;80:366-73.

2. Sebastian P, Cherian T, Ahamed MI, Jayakumar KL, Sivaramakrishnan P. The sternomastoid island myocutaneous flap for oral cancer reconstruction. Arch Otolaryngol Head Neck Surg 1994;120:629-32.

3. Parkash S, Ramakrishnan K, Ananthakrishnan N. Sternomastoid based island flap for lining after resection of oral carcinomas. Br J Plast Surg 1980;33:115-8.

4. Ariyan S. Pectoralis major, sternomastoid, and other musculocutaneous flaps for head and neck reconstruction. Clin Plast Surg 1980;7:89-109.

5. Ariyan S. One-stage reconstruction for defects of the mouth using a sternomastoid myocutaneous flap. Plast Reconstr Surg 1979;63:618-25.

6. Chow TL, Lam CY, Chiu PW, Lim BH, Kwok SP. Sternomastoidmuscle transposition improves the cosmetic outcome of superficial parotidectomy. Br J Plast Surg 2001;54:409-11.

7. Siemssen SO, Kirkby B, O'Connor TP. Immediate reconstruction of a resected segment of the lower jaw, using a compound flap of clavicle and sternomastoid muscle. Plast Reconstr Surg 1978;61:724-35. 